\title{
Restaurantes coreanos en la Ciudad de Buenos Aires. Comida, cultura e identidad en la diáspora
}

ROMINA DELMONTE

Candidata a Maestra en Sociología de la Cultura y Análisis Cultural (IDAES - UNSAM)

rominadelmonte@gmail.com

\begin{abstract}
Resumo El presente artículo propone una reflexión en torno a los restaurantes coreanos como lugares donde confluyen distintas dimensiones de la construcción de la identidad de este grupo de migrantes en Buenos Aires. A partir de la hipótesis de que los restaurantes construyen un relato sobre la comida tradicional y sobre ser coreano en Buenos Aires, recuperamos el concepto de fachada (Goffman, 1974) para describir las estrategias escénicas que se ponen en juego en estos espacios. Pudimos observar que a pesar de tener características comunes, los restaurantes presentan distintas narraciones que articulan de modo diferenciado las heterogéneas configuraciones culturales de la comunidad coreana en Buenos Aires.
\end{abstract}

Palabras clave: Migración; hábitos alimentarios; restaurantes; diáspora; identidad

\section{Introducción}

T A COMUNIDAD COREANA en la Argentina cuenta con aproxiLmadamente 22.000 personas (Mera, 2012) y está compuesta por tres generaciones de migrantes. Este año 2015 cumple cincuenta años de historia. Con un tamaño menor del de su momento de esplendor (1984-1990), la comunidad está afianzada e inserta económica, institucional y educativamente, fruto de un acelerado proceso de movilidad social ascendente (Bialogorski, 2002; Mera, 1998).

En la Ciudad de Buenos Aires hay alrededor de ochenta restaurantes coreanos que ofrecen distintos tipos de comida y ambientación, aunque todos tienen en común el encontrarse en dos zonas de la ciudad y el ser exclusiva o mayoritariamente visitados por clientes de la comunidad coreana.

Siguiendo a Medina (2003), entendemos que los restaurantes étnicos son atravesados por distintas dimensiones relativas a la relación comida-migración: 1) la tensión público-privado: ubican la comida en el espacio público, pero a su vez los locales son lugares privados; 2) su localización tiene que ver con usos y construcciones del espacio urbano; 3) presentan una construcción sobre el origen y, específicamente, sobre la cocina tradicional de ese lugar y 4) son negocios rentables, un medio de vida y, por lo tanto, se encuentran atravesados por relaciones económicas

En este trabajo nos proponemos analizar las estrategias escénicas que despliegan los restaurantes coreanos en la Ciudad de Buenos Aires e indagar el rol que estos cumplen en la construcción de las configuraciones identitarias de este grupo migrante. El concepto de fachada (Goffman), en tanto serie de normas que expresan cierta puesta en valor de la realidad, 
resulta útil para abordar esta doble dimensión material y simbólica presente en estos locales. Desde esta perspectiva, los restaurantes coreanos proyectan una definición de la situación, una reivindicación de la realidad, a través de los componentes de su fachada. Por lo tanto, partimos de la hipótesis de que los restaurantes construyen un discurso que (re)crea un "nosotros" al interior de la comunidad y expresan una toma de posición sobre "qué es ser coreano" en el marco más amplio de la identidad diaspórica.

El trabajo de campo que fundamenta empíricamente este artículo se realizó entre julio y noviembre de 2014. En primer lugar, se construyó un registro de restaurantes coreanos en la Ciudad a través de entrevistas con informantes clave y de información disponible en la página web de la Cámara de Empresarios Coreanos en Argentina ${ }^{1}$. Para poder visualizar la presencia y distribución de estos locales en el espacio urbano se elaboró un mapa. Se visitaron quince restaurantes y se realizó una labor etnográfica más detallada sobre tres casos que se evidenciaron como referentes de tres tipos diferenciados. Como resulta de interés para este trabajo interpretar sentidos proyectados en la puesta en escena de estos restaurantes, el trabajo de campo se orientó a la observación y registro de las características edilicias interiores y exteriores, el mobiliario, la decoración, el diseño de las cartas o menús y la comida. De forma complementaria, en el marco de la investigación ${ }^{2}$ en la que se inserta este trabajo, se han realizado entrevistas a dueños y clientes de restaurantes coreanos.

Para analizar el rol de los restaurantes en la construcción de la identidad diaspórica, comenzamos primero con algunos aportes teóricos sobre el análisis de hábitos alimentarios en contextos migratorios. En segundo lugar, realizamos una breve caracterización del proceso migratorio coreano en el país, la instalación de la comunidad coreana en Buenos Aires y la construcción de identidades diaspóricas. En tercer lugar, se describen algunas características generales de los restaurantes: localización en la ciudad, características edilicias, tipos de comida ofrecida, caracterización de dueños y empleados, etc. Por último, profundizamos en las estrategias escénicas particulares de tres restaurantes.

\section{Comida y migración}

Siguiendo a Calvo (1982), entendemos que los hábitos alimentarios de un grupo dan cuenta del pasado individual y colectivo y, a su vez, están ligados a los sistemas de producción, consumo y comunicación de los que también son parte. La alimentación no se limita a la necesidad biológica de nutrirse, sino que conlleva implicaciones económicas, sociales, ecológicas y culturales. Por lo tanto, "la práctica alimentaria es tributaria de la manera de pensar, de sentir y de actuar de los grupos étnicos”. (Calvo, 1982: 385). Entendemos que la comida, como parte del habitus (Bourdieu, 1988), tiene la propiedad de condensar la historia acumulada de un grupo, pero también da cuenta de las tensiones y movimientos propios del mundo social. Los hábitos alimentarios son incluidos, en este sentido, en un conjunto de disposiciones y estructuras cognitivas y motivadoras más amplio que organiza la acción y que está construido a partir de particulares condiciones de existencia.

Como señalan Kaplan y Carrasco (1999:11), "el sistema alimentario de un grupo social o de un pueblo debe entenderse como una propuesta de organización de elementos bioculturales en el marco de sus relaciones sociales". En este mismo sentido, Barthes (2008) sostiene que los hábitos alimentarios significan, expresan y (re)crean una forma de vida y de entender el mundo. Por lo tanto, una cultura alimentaria es el resultado, nunca acabado, de la sedimentación de múltiples procesos (sociohistóricos, económicos, políticos, discursivos). En nuestro caso, entendemos la forma de pensar, de actuar y de sentir de los migrantes coreanos en Buenos Aires como una construcción que surge a partir de procesos históricos, en la que conviven sedimentaciones de estructuras de pensamiento tradicionales, aportes de contactos interculturales a lo largo de la historia, el legado de guerras, invasiones, división del país, influencia de occidente, así como los cambios en el estilo de vida producidos a partir de la década del '60. A todo esto se suman las diversas reorganizaciones socioculturales que trae aparejado el proceso de migración.

En el caso de este trabajo, el centro de interés no es la comida en sí misma, los ingredientes y sus preparaciones, sino los restaurantes étnicos entendidos como espacios coreanos en la diáspora (Medina, 2003). El problema del rol de estos locales en la construcción de la identidad involucra distintas dimensiones de la vida de los migrantes: hábitos alimentarios, proceso migratorio, instalación en la ciudad, trabajo. Estas construcciones gastronómicas en la esfera pública presentan diferencias con las prácticas alimentarias en el hogar y en el entorno familiar. La reflexión sobre los restaurantes es relevante ya que incorpora otras dimensiones al análisis: implica comida, pero también una apropiación del espacio público que se entrecruza con referencias a la cultura de origen en relación con estrategias económicas de supervivencia (Medina, 2003). 


\section{Coreanos en Buenos Aires. Algunas características del proceso migratorio}

Los primeros migrantes coreanos comenzaron a llegar a la Argentina en la década de 1960, pero puede hablarse de una corriente migratoria a partir de 1965. Entre los motivos que favorecieron su llegada se menciona la política de emigración que la República de Corea comenzó a aplicar a partir de 1962 con el fin de controlar o dar soluciones al problema del crecimiento de la población así como la situación política interna, marcada por un escenario autoritario y represivo, la inestable relación con Corea del Norte y las amenazas del desencadenamiento de nuevas agresiones (Sassone y Mera, 2007).

Entre 1984 y 1990 llegó la mayor cantidad de migrantes al país; el pico máximo de alrededor de 40.000 personas se alcanzó en 1990 (Mera, 2012). Prácticamente todos provenían de Corea del Sur, aunque en los primeros años llegaron unas pocas personas de Corea del Norte. A partir de mediados de la década de 1990 se produce un proceso de reemigración. Los últimos trabajos estiman en 22.000 personas el tamaño de la comunidad coreana en el país (Mera, 2012). En su trabajo sobre la migración coreana en la escuela media Argentina, Castiglione (2007) señala tres características principales de esta comunidad: a) contar con capitales propios, es una migración de inversión; b) ser una migración de tipo familiar y con importante grado de interrelaciones; y c) aunque es económica, considera no solo una mejora material, sino también educativa y de oportunidades para sus hijos.

$\mathrm{Su}$ actividad económica principal se concentra en el área textil (tanto industrial como comercial) en ciertos barrios de la Ciudad de Buenos Aires como Flores/ Floresta y, en menor medida, Once. Este último tuvo mayor importancia para la comunidad en la década de 1990 pero, con los años, los comerciantes coreanos fueron trasladando, casi en su totalidad, sus comercios a la zona de Floresta.

En cuanto a los espacios de sociabilidad comunitaria, los migrantes concentran sus asociaciones, iglesias y negocios en dos barrios: el tradicional barrio coreano de Bajo Flores, Baek-ku ${ }^{3}$ y la zona de Floresta aledaña a la avenida Avellaneda. Ambos están localizados en la zona oeste de la Ciudad de Buenos Aires. (Imagen 1)

Baek-ku es producto del largo proceso de instalación de esta comunidad y fue agrupando las residencias familiares, los servicios y comercios comunitarios. Se concentra en la avenida Carabobo (que cuadras más

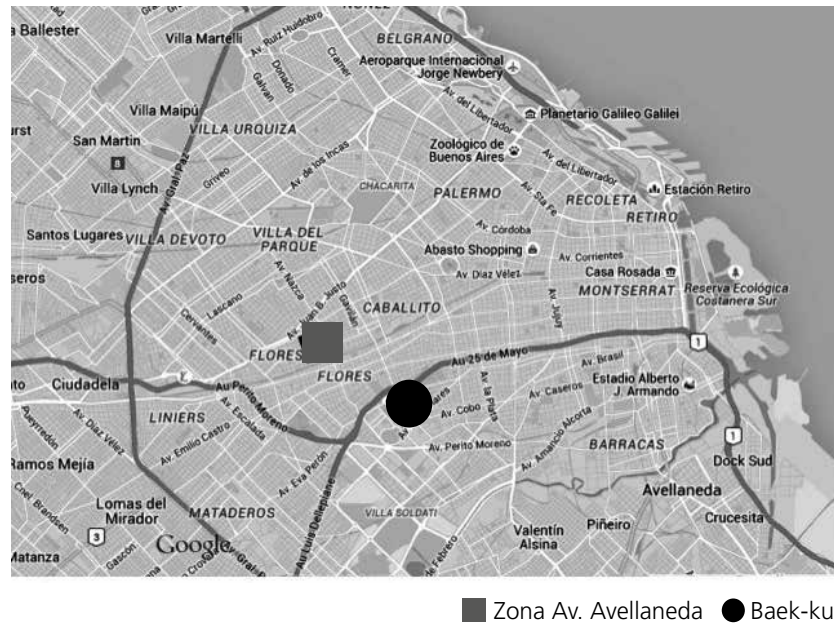

Imagen 1

tarde pasa a llamarse Corea) desde Av. Eva Perón hasta Castañares y hacia los alrededores. La avenida Carabobo es el eje comercial, en tanto que en calles cercanas se instalan las residencias. Es un barrio que se desarrolló desde y para la comunidad (Sassone y Mera, 2007).

Es una zona periférica de la ciudad y en uno de sus límites se encuentra la "villa 1-11-14". Según los migrantes entrevistados, en los últimos años aumentaron los hechos de violencia, lo que llevó a que muchos locales se mudaran a la zona de la calle Avellaneda, dejando comercios vacíos y una impronta de abandono en Baek-ku. También podría pensarse que el movimiento social ascendente de la comunidad es uno de los factores que los llevaron a trasladar parte de su vida asociativa y comunitaria a una zona algo más céntrica de la ciudad. Igualmente, en Baek-ku continúa habiendo almacenes, panaderías, restaurantes, la escuela coreana (ICA) y las iglesias evangélicas. Como estos últimos inmuebles cuentan con una infraestructura de envergadura, encuentran mayores dificultades para mudarse. Los días con mayor movimiento son los fines de semana, debido principalmente a la actividad en las iglesias.

En este contexto de depreciación del barrio, en el último año notamos algunos cambios. La Asociación Barrio Coreano está llevando adelante algunas estrategias para atraer al público extra comunitario mediante, por ejemplo, talleres abiertos a la comunidad e, incluso, el diseño de un mapa con los principales comercios e instituciones comunitarias, que puede encontrarse en la sede de la Asociación ${ }^{4}$, en algunos comercios y en su perfil de facebook ${ }^{5}$. Consideramos que, posiblemente, esta estrategia se inspire en el Barrio Chino, que utiliza la diferencia cultural como marca de consumo particular dentro de la ciudad.

3 Baek-ku significa 109 en coreano. Este nombre que la comunidad le adjudicó al barrio hace referencia al colectivo que lo conecta con el centro de la Ciudad.

4 Ubicada en Av. Carabobo al 1500.

5 https://www.facebook.com/ArgentinaBarrioCoreano 
La zona aledaña a la calle Avellaneda, ubicada en el barrio de Floresta, a unas veinte cuadras de Baek-ku, fue creciendo en los últimos años en alrededor de la actividad textil. El eje comercial principal se ubica en dicha avenida, aunque los comercios comunitarios se encuentran en las calles aledañas. Pese a no ser un barrio formal y no tener límites definidos, podríamos ubicar esta zona dentro de los límites de la Av. Nazca y E. Lamarca, y desde Páez hasta Bacacay; Morón es una de las calles con mayor presencia de locales de consumo comunitario.

Esta zona fuertemente comercial comenzó reuniendo locales de la industria textil de dueños coreanos y cada vez fue cobrando mayor relevancia. Pese a encontrarse relativamente cerca de Baek-ku, tiene mejor acceso a los medios de transporte, puesto que se encuentra a pocas cuadras de la línea A del subterráneo y por la avenida Rivadavia circulan numerosas líneas de autobuses hacia distintos puntos de la Ciudad. A causa del proceso descripto en Baek-ku y del crecimiento comercial, ya se pueden encontrar restaurantes, peluquerías, almacenes, panaderías, salones de belleza, inmobiliarias, consultorios médicos, etc. (de y para coreanos). Hoy, un poco más de la mitad de los restaurantes se ubica en esta zona. De modo que comenzó siendo un barrio puramente comercial, pero fue adquiriendo otras funciones, entre ellas, también la de residencia. A diferencia de Baek-ku, la zona de Avellaneda se caracteriza por una fuerte actividad durante los días laborables (de 10 a 18 hs, hora en que cierran los locales) y los sábados por la mañana. $\mathrm{Al}$ ser un punto neurálgico para la compra de productos textiles, no solo de la ciudad sino también a nivel nacional, la sociabilidad se organiza alrededor del mundo del trabajo. Mientras que en Baek-ku el paisaje es residencial, arbolado y con edificios bajos, la zona de Avellaneda es comercial, con una alta circulación de personas.

Este tipo de instalación concentrada dentro de la ciudad es una de las características que nos permiten ubicar a la migración coreana como diaspórica. En el próximo apartado profundizaremos este aspecto, pero cabe destacar que los barrios étnicos cumplen funciones de contención afectiva y protección en un entorno diferente, a partir de la (re)creación de valores y tradiciones (Mera, 2011). No obstante, pese a la permanencia de ciertas pautas culturales, entendemos que el proceso de instalación se encuentra abierto al cambio y al movimiento propio del mundo social. Por ejemplo, el surgimiento de la zona de la Av. Avellaneda se encuentra en sintonía con las características que van a ir adquiriendo las relaciones sociales en el interior de la comunidad y con la sociedad mayoritaria: mantenimiento de redes comunitarias, junto con mayor integración social y económica y un movimiento social ascendente.

\section{Migración e identidad diaspórica}

Como adelantamos más arriba, entendemos a la migración coreana como diaspórica (Mera, 2011). Siguiendo a Brubaker (2005), el concepto de diáspora ha sido crecientemente utilizado en los últimos años, para hacer referencia tanto a las diásporas clásicas, como la judía, la griega o la armenia como, también, y de manera creciente, a distintos procesos que involucran movimiento de personas, construcción de identidades y mantenimiento de lazos de algún tipo con el país de origen. De las distintas aproximaciones al concepto (Brubaker, 2005; Choi, 2003; Clifford, 1994; Cohen, 1997; Sheffer, 2003, entre otros), en nuestro caso consideramos centrales las siguientes características que señala Bruneau (2004): 1) la población considerada se encuentra dispersa en distintos lugares; 2) la elección del país de destino se realiza en función de la estructura de cadenas migratorias que ligan a los migrantes con otros ya instalados; 3) las nuevas poblaciones se integran en el país receptor sin asimilarse y 4) los grupos migrantes dispersos conservan y desarrollan relaciones de intercambio entre ellos, con el país de origen y con los otros polos migratorios.

En cuanto a la dimensión territorial, como señala Mera (2011) y como pudimos observar en nuestro trabajo de campo, la comunidad coreana se encuentra dispersa en el espacio. En el caso de nuestros entrevistados, sus trayectorias migratorias incluyen distintos destinos: Argentina, Paraguay, Brasil, México o Estados Unidos y es muy habitual que estén en contacto (más aún con el creciente desarrollo de las TIC $^{6}$ ) con familiares que viven en otros países. Esta dispersión, como mencionamos, va acompañada de la concentración en barrios étnicos dentro de las ciudades.

Grimson (2011) señala la profunda imbricación entre el carácter diaspórico de una migración y la identidad, identificación o "sentimiento de pertenencia". La diáspora habilita la creación de identidad distintiva, que incluye los procesos de movilidad espacial (Mera, 2011). En este proceso lo imaginado adopta una importancia central: "La diáspora, en tanto fenómeno transnacional, pone de relieve el territorio como entidad simbólica, constituida por tres ejes: los anclajes nacionales (de residencia), la conciencia nacional (de origen) y la identidad producto del intercambio (comunidades de otros países)" (Mera, 2011:5). De esta manera, la construcción de la identidad diaspórica se apoya en el origen común (territorio de origen más o menos mítico) y, sobre todo, en esa entidad simbólica, el "espacio metafórico" conformado por la red de lugares donde se encuentran las comunidades de la diáspora, articulando lugares distantes espacio-temporalmente para lograr 
una estrategia presente. En el caso de los restaurantes, la hipótesis que proponemos sostiene que presentan una construcción sobre lo coreano, articulando estos lugares distantes espacio-temporalmente, a través de un trabajo de imaginación (Appadurai, 2001) y en el marco de un habitus (Bourdieu, 1988).

La diáspora introduce la fuerza de la imaginación en la construcción de identidad en las actuales sociedades. Appadurai (2001) sostiene que la imaginación deja de estar relegada al campo del arte y la expresión, para estar presente en la realidad cotidiana de las personas. Con este concepto propone diferenciarse del concepto de habitus, al que considera demasiado rígido: "Para grandes grupos humanos, estas mitografias sustituyen la fuerza glacial del habitus por el ritmo acelerado de la improvisación.” (Appadurai, 2001: 9).

Tanto el trabajo de imaginación como el concepto de habitus tienen una dimensión performativa y conectan prácticas culturales con procesos de construcción de identidades. Por lo tanto, nos permiten pensar la (re) creación de pautas culturales (los hábitos alimentarios y, en este caso específico, la problemática de los restaurantes étnicos) en un contexto diaspórico. El trabajo de imaginación incorpora la transnacionalidad y la presencia de los medios electrónicos en la construcción de subjetividades, mientras que el habitus introduce el papel de las disposiciones que son producto de particulares condiciones de existencia, la historia acumulada que también está abierta al movimiento.

Estos conceptos también nos permiten comprender procesos como la persistencia de valores y prácticas culturales a lo largo del tiempo y a través de las distintas generaciones, que Brubaker (2005) señala como central en la diáspora. Esta persistencia no se entiende de forma mecánica, sino más bien como fruto de un proceso de negociación, tensión y conflicto. Proceso en el que entendemos que opera un trabajo de imaginación y ciertas disposiciones y estructuras cognitivas y motivadoras parte de un habitus. Las experiencias e imaginarios de los migrantes coreanos en Buenos Aires ligados a Corea son heterogéneos. Se ha encontrado en el trabajo de campo que la relación intergeneracional que, una vez más, asume la forma de diálogo y conflicto, ejerce un rol fundamental en la construcción de imaginarios ligados a Corea en general y, en particular, a su tradición alimentaria. Pero, también, las características del proceso migratorio ejercen su influencia en la reconfiguración de las prácticas alimentarias y la construcción de sentidos asociados, favoreciendo ciertas formas de comprar, preparar y consumir alimentos, en sintonía con representaciones sobre las relaciones dentro de la familia, entre las distintas generaciones, entre los géneros, así como con la conformación de sentimientos de pertenencia.

Volviendo al concepto de identidad, Hall (2011) la define desde una perspectiva deconstructivista y con énfasis en lo discursivo. La entiende como un proceso nunca terminado, una construcción a partir de determinadas condiciones materiales de existencia pero que, a su vez, opera en el marco de la contingencia: una vez consolidada no anula la diferencia. Es más, se construye y actualiza a través de la diferencia: necesita lo que queda afuera, su exterior constitutivo, para consolidar el proceso. Por lo tanto, hay diferencia con el afuera y también hacia adentro. "Aunque parecen invocar un origen en un pasado histórico con el cual continúan en correspondencia, en realidad las identidades tienen que ver con las cuestiones referidas al uso de los recursos de la historia, la lengua y la cultura en el proceso de devenir y no de ser; no "quiénes somos" o "de dónde venimos" sino en que podríamos convertirnos.” (2011:17). Como señala Arfuch (2005), de este modo, la identidad es una construcción nunca acabada que también tiene una dimensión narrativa, simbólica, que se construye en el discurso. Es en este sentido que proponemos que los restaurantes coreanos cumplen un rol en la construcción de este relato sobre qué es ser coreano-argentino.

\section{Restaurantes coreanos en la Ciudad de Buenos Aires}

Los restaurantes étnicos muestran un "nosotros" particular hacia el exterior, construyen un espacio coreano en la diáspora, habilitan la interculturalidad y el contacto con el otro y, a la vez, son un negocio, un aspecto cultural vendible y rentable, de lo que puede extraerse un beneficio comercial y, por lo tanto, constituyen un medio de vida (Medina, 2003). Presentan algunas particularidades que los diferencian de otros "restaurantes étnicos" de la ciudad y en estas características encontramos distintas dimensiones para abordar el problema de la construcción de la identidad. A continuación, las detallamos.

Como mencionamos más arriba, se encuentran concentrados en dos zonas de la ciudad (Imagen 2): el barrio Baek-ku y la zona de la calle Avellaneda. Salvo una excepción, el restaurant Bi-Won, que se ubica en el barrio de Balvanera, cercano a la zona de Once

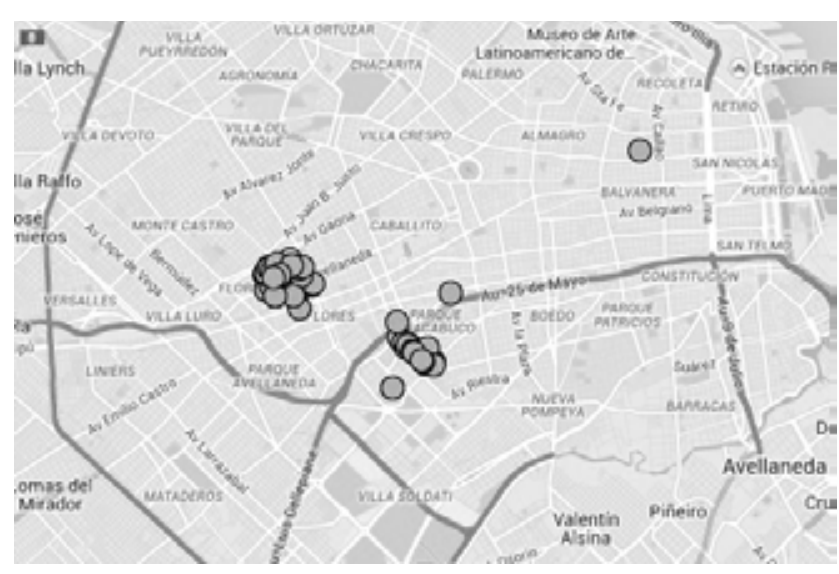

Imagen 2 
y que, justamente, es uno de los más orientados a un público extracomunitario: su menú está en español y en inglés y los cubiertos son occidentales. Entendemos la existencia de estos espacios públicos, los restaurantes, como parte de una construcción y utilización de la ciudad (Medina, 2003). En este sentido, encontramos una relación entre su concentrada localización y el proceso de instalación de la comunidad coreana y, por lo tanto, con la vida social, económica e institucional. Que los restaurantes estén concentrados ayuda a articular cierta idea de vida asociativa y comunitaria dentro del espacio urbano. Como señalamos previamente, el barrio Baek-ku unificó las funciones residenciales, comerciales y culturales étnicas y, en cierta medida, aún lo hace, pero hoy vemos cómo esto se desdobla con la zona de la calle Avellaneda. Pero teniendo en cuenta las características mencionadas anteriormente de Baek-ku, su importancia histórica y simbólica, podemos sostener que es un eje principal donde se articula la identidad de la comunidad coreana en Buenos Aires. Los restaurantes de Baek-ku se localizan en su mayoría sobre su arteria comercial principal: la calle Carabobo, lugar de paseo histórico para la comunidad. Los de la zona de la calle Avellaneda, en cambio, se distribuyen por las calles aledañas a esta arteria principal y, en muchos casos, cumplen la función de brindar opciones de almuerzo (en los restaurantes o por delivery) a los miembros de la comunidad que trabajan en la zona. Mientras que en Baek-ku la calle principal está orientada al consumo étnico y tiene un sentido afectivo para la comunidad, la calle Avellaneda es un punto neurálgico de la ciudad para la compra de productos textiles, netamente comercial, en el que participan miembros de la sociedad mayoritaria y a la que, incluso, llegan micros del interior del país como parte de "tours de compras". Por esta razón entendemos que se ubican en las calles aledañas. Cabe destacar que ningún restaurant coreano se ubica en los polos gastronómicos de la ciudad (Palermo, Las Cañitas, Puerto Madero, Recoleta, San Telmo). En el imaginario de la sociedad mayoritaria, la comida coreana sigue siendo algo desconocido.

En cuanto a la visibilidad, una gran cantidad de los restaurantes coreanos no tiene ninguna señalización en el exterior que los identifique como tales, algunos inclusive, parecen residencias particulares desde el exterior y otros solo tienen letreros en coreano. Esta característica da cuenta de la orientación hacia un consumo. En sintonía con lo anterior, un pequeño número aparece en las guías gastronómicas de la ciudad.

Pese a estas dos características, algunos restaurantes se presentan más proclives a buscar un público no comunitario mediante la inclusión de carteles en el exterior, menús en español e, incluso, en algunos casos, fotos ilustrativas de los platos o apareciendo en guías o publicaciones sobre comida o en las redes sociales. Dentro de esta tendencia ubicamos la iniciativa de la Asociación del Barrio Coreano anteriormente citada (mapa con ubicación y descripción de los restaurantes, presencia en redes sociales, etc.)

En cuanto a los clientes, la mayoría son de origen coreano, a pesar de que cada vez más los visita un público extracomunitario. Esta característica se relaciona con las anteriormente citadas. Los comercios, bares y restaurantes de Baek-ku son de y para coreanos. También encontramos que esta característica se verifica en la mayoría de los restaurantes de la zona de Avellaneda (lo que no sucede con los comercios textiles). Como mencionamos más arriba, las esferas laborales, familiares, religiosas, educativas y de esparcimiento del barrio étnico posibilitan recorridos e interacciones cotidianas en los cuales están relativamente protegidos del diálogo conflictivo y la negociación con otros grupos (Sassone y Mera, 2007).

En cuanto a los dueños y empleados, en la mayoría de los casos, los primeros y quienes dirigen las cocinas son coreanos, en tanto que los mozos y el personal que ejecuta las tareas de cocina y limpieza es de origen boliviano, paraguayo, peruano y, en menor medida, argentino. $\mathrm{O}$ sea que quienes deben estar en contacto con el público tienen un manejo fluido del idioma y los códigos de la sociedad mayoritaria. Aunque la mayoría de los clientes son coreanos, creemos que esta característica se debe a que de esta manera se encuentra una ventaja en la comunicación con el extracomunitario. Asimismo, los últimos son trabajos de menor remuneración y prestigio; algunos dueños mencionaron la gran diferencia en el costo de la mano de obra.

En cuanto a los horarios, los que abren por la noche, en general abren y cierran temprano: entre las 18 y 23 hs., lo que da cuenta del hábito coreano de cenar más temprano que lo habitual en la sociedad receptora. La experiencia del restaurant étnico no solo involucra ingredientes y preparaciones, sino una serie de hábitos asociados al comer. Aunque en algunos más que en otros, ir a un restaurante coreano es una forma de viajar a Corea $-\mathrm{O}$ a ese paisaje imaginado, en el sentido de Appadurai (2001) - por un rato, ingresando a un espacio que incluye prácticas y símbolos particulares.

En este acercamiento a la problemática de los restaurantes coreanos en la Ciudad de Buenos Aires, distinguimos un tipo de establecimientos que llamó nuestra atención y que encontramos especialmente fecundo para reflexionar sobre la construcción de la identidad en la diáspora. En calle Avellaneda se fueron estableciendo en el último tiempo una serie de bares orientados al consumo de café con una estética norteamericana. Es llamativa la referencia a cadenas al estilo de "Starbucks", tanto en las preparaciones, en el menú e inclusive en la vajilla, descartable y estéticamente similar. La ambientación es muy cuidada y de estilo occidental. Los dueños y personas a cargo son jóvenes de la comunidad, mientras que como en los otros casos mencionados, el personal de servicio es extracomunitario. En próximos trabajos analizaremos en mayor profundidad este fenó- 
meno y sus relaciones con la modificación de los hábitos alimentarios en Corea del Sur, la globalización, la interculturalidad y la construcción de identidad diaspórica con lazos transnacionales.

\section{La construcción de relatos sobre el origen. La puesta en escena de tres restaurantes coreanos}

Más allá de las características generales descriptas más arriba, analizaremos la fachada (Goffman, 1974) de tres restaurantes coreanos para analizar las distintas estrategias a través de las cuales se construyen relatos sobre la coreaneidad. La fachada muestra una serie de normas que expresan cierta puesta en valor de la realidad, una posición. Interpretar esos signos presentes en las características de cada una de estas fachadas, nos permite acceder a formas de pensar y sentir de la comunidad coreana en Buenos Aires. Para alcanzar tal fin, a continuación se describen: ubicación, horarios, medio exterior e interior, regiones (Goffman, 1974) y características del menú.

\section{La ubicación de los restaurantes coreanos en la Ciudad}

Como señalamos anteriormente, los restaurantes coreanos en Buenos Aires se concentran en dos barrios. Los tres restaurantes que describimos en este artículo se encuentran dentro de estos barrios, en zonas con diferentes características.

길정' se ubica en la calle Campana, a tres cuadras de la avenida Avellaneda, centro comercial de la industria textil que desarrolla la comunidad coreana en Buenos Aires. Pese a estar a pocos metros de esta arteria comercial, esta cuadra ya no cuenta (como las más próximas a la avenida) con la presencia de locales textiles, hay casas bajas y al lado un taller mecánico. El restaurant funciona únicamente al mediodía. Por lo tanto está orientado al público que se encuentra trabajando en la zona.

Desde el exterior no hay ningún signo que indique que ahí funciona un restaurant, aunque sí hay un pequeño detalle que da cuenta de la pertenencia comunitaria: arriba de la puerta se encuentra un farol con el nombre del restaurant en coreano (Imagen 3). Es solo para entendidos.

Al ingresar se accede a una escalera. El restaurant se encuentra en el primer piso. Sumando de este modo, más invisibilidad.

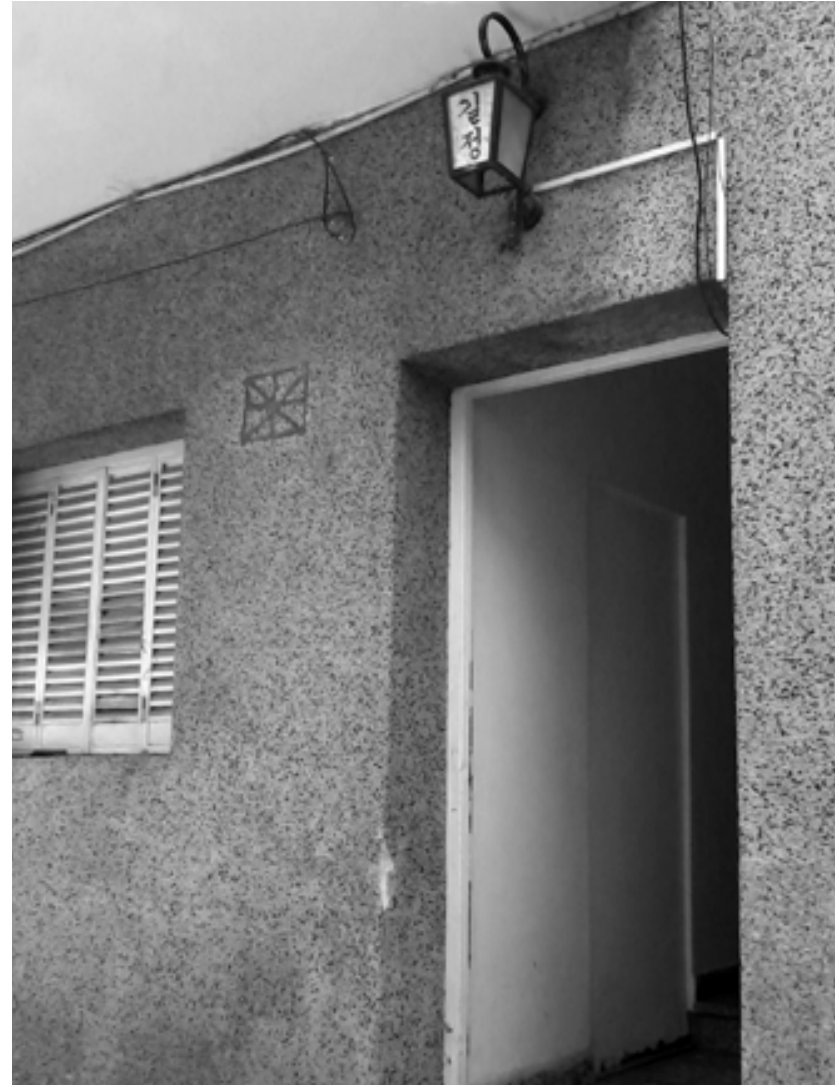

Imagen 3

El segundo restaurant, Kyung Mi Jong ${ }^{8}$, se encuentra en los límites de Baek-ku, sobre Pumacahua, una calle residencial, y es el único comercio de la cuadra. Aun así, está a pocas cuadras del tradicional barrio coreano y de los templos evangélicos. En la semana abre únicamente de noche, los fines de semana también al mediodía. Estos días son los más activos, ya que muchos comensales concurren a la salida los servicios de las iglesias evangélicas coreanas de la zona.

Desde afuera no se visualiza el interior, se accede a través de una puerta de hierro que siempre está cerrada. Se indica que es un restaurant a través de dos carteles: uno en madera, de tipo más tradicional escrito únicamente en coreano y otro en un costado en coreano y español (Imagen 4).

El tercero, Una canción coreana, se ubica sobre la Avenida Carabobo, arteria principal de Baek-ku y donde se encuentra la mayoría de los restaurantes del barrio, es el quinto en la cuadra.

Cuenta con un gran ventanal y puerta vidriados, a través de los cuales se ve perfectamente el interior. Es el único de los tres cuyo nombre está en español y proviene del título de una película que documenta la vida de su dueña ${ }^{9}$. Para acceder hay que tocar un timbre. (Imagen 5)

7 Kiljeong, nombre propio que hace referencia al apellido de los dueños. Decidimos nombrarlo tal cual aparece en su pequeño letrero-farol. 8 경미정 en caracteres coreanos. Es también un nombre propio

9 "Una canción coreana" dirigida por Yael Tujsnaider y Gustavo Tarrío. Trailer: https://www.youtube.com/watch?v=8MAQrSayPuc 


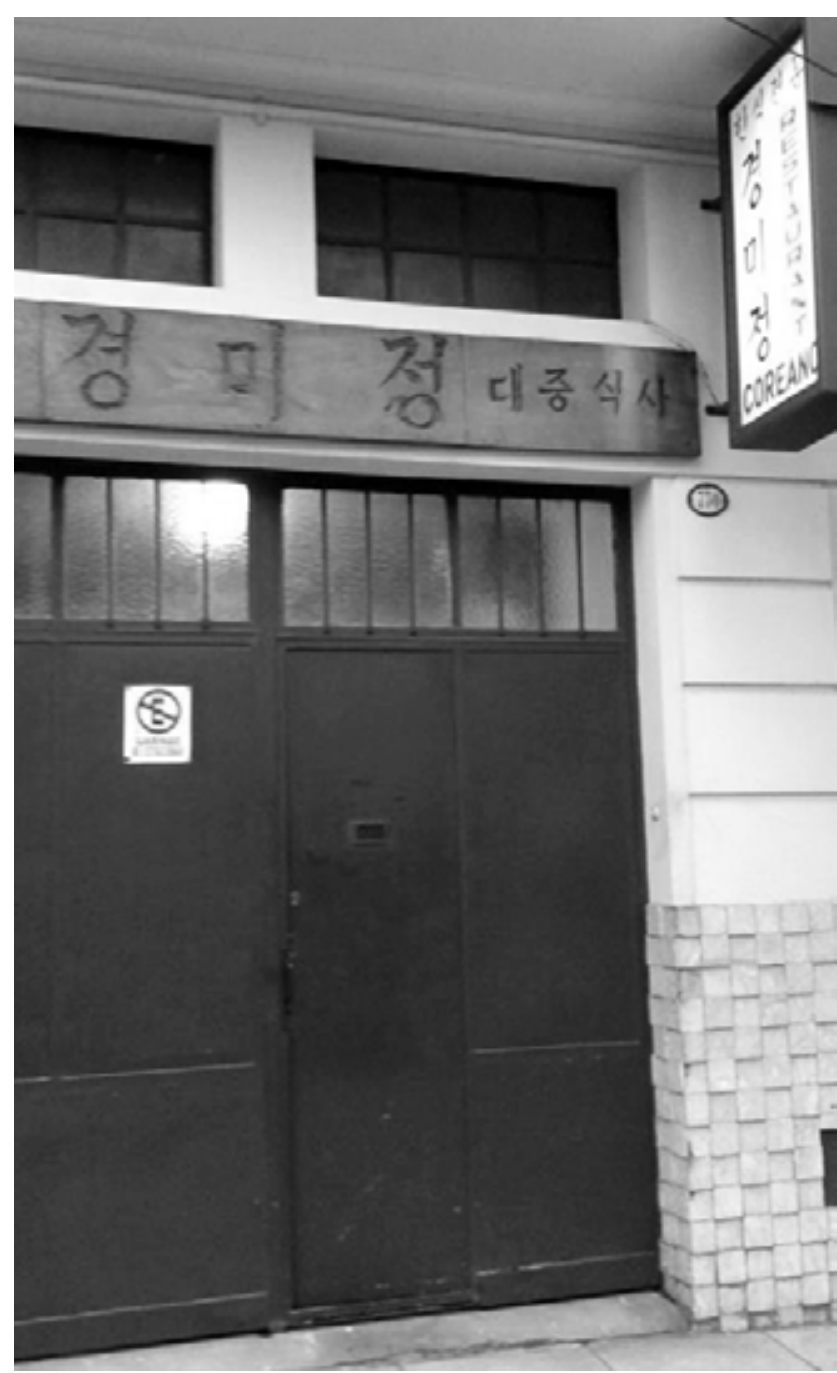

Imagen 4

\section{Estar en Corea por un rato. El diseño interior de los restaurantes}

Goffman (1974) sostiene que el medio es aquello conformado por los elementos propios del trasfondo escénico, que proporciona el escenario y utilería para el flujo de acción humana que se desarrolla dentro de él. Entendemos que esos elementos tales como la distribución del espacio, el mobiliario, la decoración, la vajilla son signos dentro del discurso más amplio que construye cada uno de estos restaurantes en torno a la comida coreana y a la coreaneidad. En 길정, la distribución de los ambientes es más típica de una casa que de un restaurant. Al subir la escalera se encuentra el salón principal. Aquí hay tres mesas grandes (para ocho personas) que, en general, se comparten, una barra donde se ubica la caja, un mueble con platos y vajilla, un reloj de pared, un tv y dos dispensers de agua fría y caliente. Luego hay otro cuarto contiguo (que se comunica con este primero por una ventana) y a través de un pasillo se accede al tercero, que da hacia el frente (tiene balcón). En este hay cuatro mesas más pequeñas, para cuatro personas.

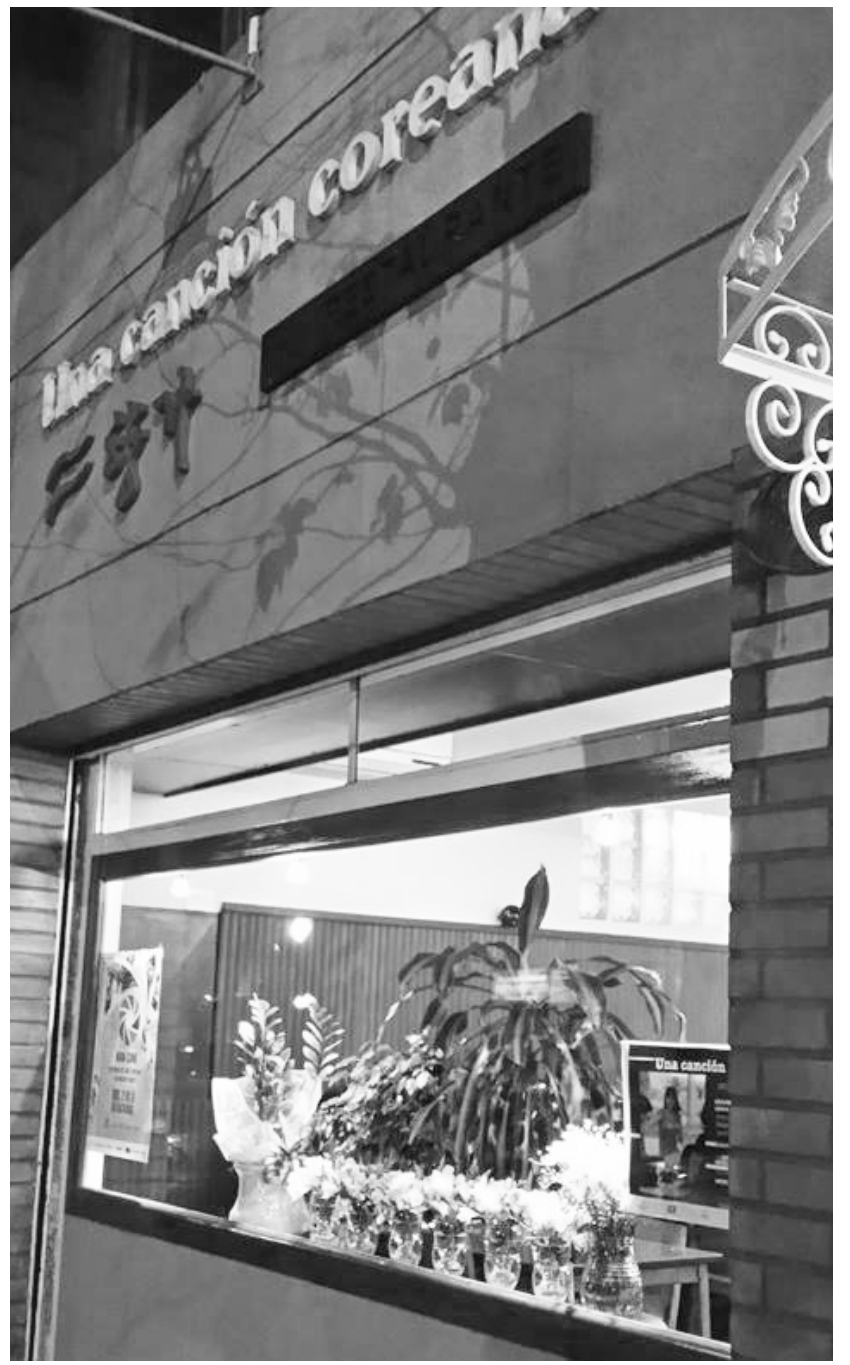

Imagen 5

Las mesas son de fórmica marrón y no llevan manteles, las sillas también marrones pero de metal. La decoración es casi inexistente.

En el caso de Kyung Mi Jong, el espacio se organiza en un salón principal con siete mesas para ocho personas y un salón cerrado, más pequeño e íntimo (Imagen 6). Esta distribución reproduce la costumbre coreana de incluir espacios más íntimos para ciertos eventos. Las mesas son también de fórmica y las sillas de madera. La decoración es sobria y predomina la madera en algunas paredes revestidas y adornos colgantes. En el salón reservado, se encuentran algunos adornos coreanos tradicionales. Por lo tanto, podemos asumir que este espacio expresa doblemente una idea tradicional de lo coreano: tanto por ser un lugar privado dentro del restaurant como por sus detalles de decoración en madera que remiten a una idea de la antigua Corea rural. La iluminación es fuerte y pareja.

Una Canción coreana cuenta con un único salón. Las mesas son más pequeñas y pueden unirse si vienen grupos más grandes, pero están dispuestas para dos o cuatro comensales. Tanto las sillas como las mesas son de madera, de mayor calidad que en los dos casos anteriores. La decoración es sobria, pero todos los materiales aparentan ser de calidad. Se destaca (por su tamaño, 


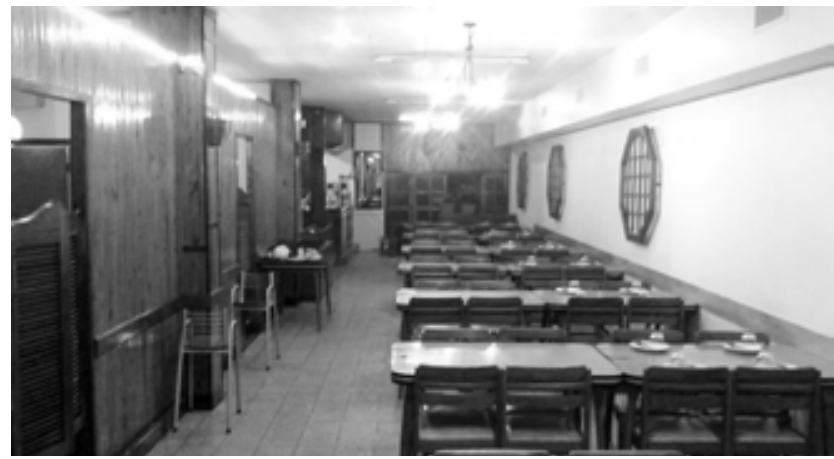

Imagen 4

ubicación y por estar especialmente iluminado) un arreglo floral natural al final del salón, que se renueva asiduamente (Imagen 7). La iluminación es tenue. La limpieza es notable: todo, incluso los baños, está impecable. Invita a quedarse, a pasar más tiempo, y remite a ideas más hedonistas sobre el comer.

\section{Mostrar/Ocultar. Las regiones donde sucede la acción}

En términos de Goffman (1974), una región es todo lugar limitado, hasta cierto punto, por barreras antepuestas a la percepción. La región anterior es el lugar donde tiene lugar la actuación. La región posterior, o "trasfondo escénico", en cambio, es ese otro lugar al que no accede el auditorio (en este caso comensales), donde el actuante puede "sacarse la máscara", donde rigen otras reglas para la actuación y la expresividad es menos ritual; en esta región aparecen los elementos suprimidos en la “anterior". En el caso de los restaurantes, es la cocina.

En el restaurante de la calle Campana, una puerta abierta desde el salón principal comunica con la cocina. Se puede ver y escuchar qué sucede tanto como el marco de una puerta lo permite. No hay acciones tendientes a reforzar la separación de estas dos regiones. Un hecho llamativo sobre el cual reflexionar son los usos de las regiones. En una de las observaciones se verificó lo siguiente: en un horario cercano al cierre, cuando ya eran pocos los clientes presentes, la dueña y sus hijas se pusieron a cocinar mandu (empanaditas de masa de trigo con distintos rellenos, que incluyen cerdo y vegetales) en una de las mesas del salón principal, con lo que anularon la separación entre regiones. Al dar una sensación hogareña, configuraron una construcción escenográfica más próxima a la de una casa que a la de un comercio. En este planteamiento escénico la comida es el elemento principal: a este restaurante se va a comer coreano en el medio del ajetreo laboral, la comida llega rápido, se come rápido y se vuelve al trabajo.

En Una canción coreana, la separación entre regiones es total. No hay manera de percibir nada de lo que

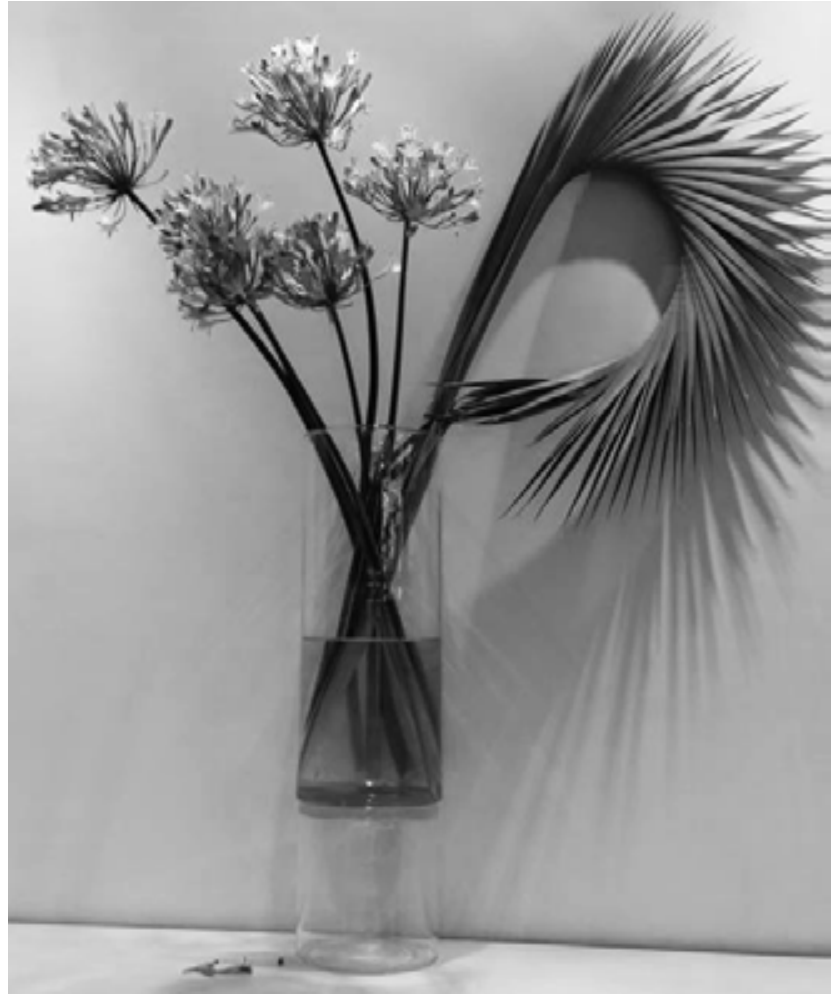

Imagen 5

sucede en la región posterior. En concordancia con el mayor énfasis puesto en la decoración, la amabilidad de la atención, la decoración de los platos, la región anterior es una puesta en escena que emana mayor profesionalismo y distancia. En esta configuración espacial hay un "nosotros" y un "otro" bien diferenciados.

Kyung Mi Jong se encuentra a mitad de camino entre los dos casos anteriores. En este caso hay dos lugares identificables como de región posterior: la cocina y la parrilla. La cocina se encuentra abierta y se accede desde el salón, está separada solamente por una barra. La parrilla está en el exterior, pero en el camino a los baños; no se percibe desde el salón, pero cualquier miembro del auditorio puede acceder a esta región en cualquier momento. Hay una separación entre elenco (dueños y empleados del restaurant) y auditorio (clientes), pero es débil y flexible.

\section{El auditorio: los clientes}

"Creo que vienen a comer acá porque no conozco ningún coreano que pueda estar más de una semana sin comer comida coreana", señala el dueño de uno de los restaurantes.

En los tres casos analizados, la gran mayoría de los clientes pertenece a la comunidad coreana, mientras que en 길정 son casi exclusivamente coreanos, en Una canción coreana se observa una mayor presencia extra-comunitaria.

En 길정, en general los grupos de comensales son pequeños, de dos o tres personas, inclusive hay algunos 
comensales solitarios. La mayoría son hombres, presumiblemente compañeros de trabajo. La atmósfera es de "estar de paso, estar pensando en otra cosa", la comida dura algunos minutos y los clientes están atentos a los teléfonos celulares.

En Una canción coreana los grupos son algo más grandes que en el caso anterior, sin llegar a ser numerosos: familias, parejas, amigos. Se respira una atmósfera de mayor énfasis en la sociabilidad. Más allá de la costumbre coreana de comer rápido, los tiempos se perciben más relajados y hay más charla entre los comensales. Es a destacar que la página de Facebook de este restaurant dedica especial atención a los clientes, incluyendo fotos y descripciones de los mismos. Pese a que la gran mayoría de los clientes son de la comunidad coreana, la mayoría de los retratados que aparecen en la página son extra-comunitarios.

Kyung Mi Jong, al tener la particularidad de funcionar por las noches y los fines de semana también al mediodía, es visitado por grupos familiares y de amigos. Pero a diferencia de Una Canción coreana, la presencia de extra-comunitarios es muy limitada. Los sábados y domingos son los días más concurridos, en los que almuerzan grupos luego de los servicios de las iglesias evangélicas coreanas de la zona.

Las diferencias entre los comensales de los tres restaurantes parecieran orientarse a distintos momentos del comer, distintas maneras (que conviven) de ser coreano en Buenos Aires. Aunque en el caso que más se encuentra relacionado con el trabajo (길정), la presencia femenina se encuentra más limitada.

\section{El menú: la construcción de una cocina coreana}

Kaplan y Carrasco (1999) entienden la tradición alimentaria como el conjunto de normas y prácticas compartidas por un grupo en un período vivido o imaginado como estable, que aporta contenido y sentido a su autopercepción en el presente. $\mathrm{O}$ sea, que se refiere al origen y al recuerdo, y que se va a "readaptar como puente entre el destino y la situación presente. Se adecúa para ser utilizada como autopresentación" (1999: 12). De este modo, la tradición alimentaria es un discurso, una narración que liga a los procesos sociohistóricos que conforman el sistema ideológico a través del cual se comprende el mundo, con el presente y el futuro; a través del hacer, del uso, de las prácticas.

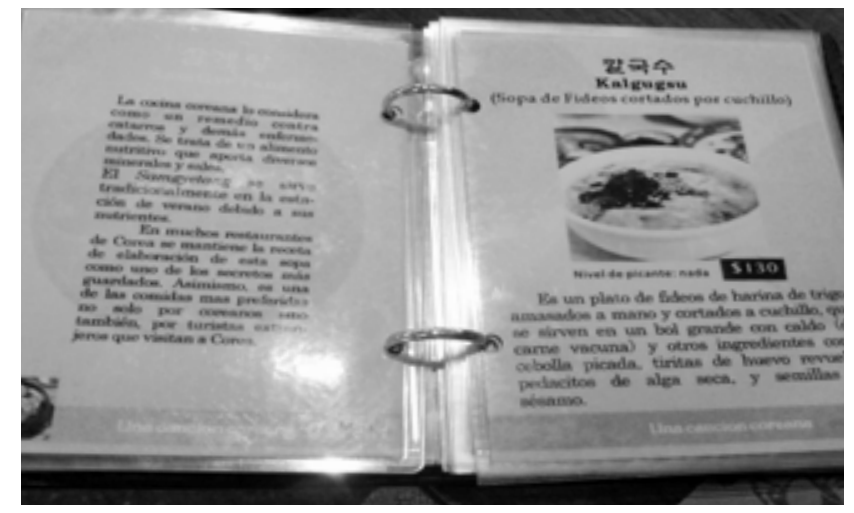

Imagen 8

Los restaurantes coreanos de Buenos Aires colocan en el espacio público de la ciudad, distintos relatos e imágenes sobre qué debe tener una comida para ser coreana.

Kyung Mi Jong no tiene un menú por escrito porque no hay distintas opciones para pedir. Únicamente se sirve galbi (tira de asado marinada y cocinada a la parrilla), acompañado por diez banchan ${ }^{10}$ y puede repetirse todas las veces que se quiera. La carne se cocina en la parrilla ubicada en el exterior. Los banchan los preparan el dueño y su madre en la cocina que se encuentra abierta al salón.

En 길정 el menú es una hoja plastificada, está únicamente escrito en coreano y cada plato está indicado con un número. Hay diez opciones de comida incluyendo carnes, pescado y sopas. Todas las comidas están previamente cocinadas, ya que llegan en pocos minutos a la mesa, junto con el bowl de arroz, sopa y alrededor de seis banchan.

El menú de Una canción coreana está orientado a un público extracomunitario. Se indica el nombre del plato en coreano y en español; y en este último también se detallan los ingredientes, el nivel de picante y alguna descripción sobre la historia del plato, en qué situaciones se come, quiénes suelen prepararlo. De este modo, se presenta una narración sobre la comida y la cultura coreanas, no solo a través de los platos y la disposición escenográfica del local, sino también a través de los relatos del menú (Imagen 8).

\section{Notas finales. Construcción de múltiples relatos coreanos en la diáspora}

Los restaurantes étnicos muestran un nosotros al exterior, a la vez que expresan y recrean pautas culturales,

10 반찬. No tienen un correlato exacto en la comida occidental. Desde un ojo externo se presentan como acompañamientos, pero son pequeños platos de distintas preparaciones (cerdo, pescado, carne vacuna y vegetales) realizadas con distintos métodos de cocción (al vapor, salteados, hervidos, grillados, disecados, crudos y fermentados). Cada uno de los chop (unidades de banchan) idealmente no debe repetirse ni en cuanto a ingredientes ni en cuanto a métodos de cocción. Los banchan son servidos de forma comunal en el centro de la mesa. Cada uno va tomando el bocado que va a comer. Puede haber 3, 5, 7, 9 o 12 platos 
ubicándose dentro del espacio urbano. Los restaurantes coreanos en Buenos Aires tienen características en común que los diferencian de otros restaurantes étnicos de la ciudad, pero a su vez presentan una heterogeneidad de relatos.

Encontramos en la localización de los restaurantes coreanos una relación directa con el proceso de instalación de dichos migrantes en la Ciudad. En el público que concurre, indicios de la sociabilidad comunitaria y también de las relaciones con el otro no-comunitario. En los menús ofrecidos, una expresión de los hábitos alimentarios en la diáspora. En total, una forma de recrear el relato sobre ser coreano-argentino en la esfera pública.

Los restaurantes coreanos, aún poco conocidos y frecuentados por la sociedad mayoritaria, son un espacio de protección para la comunidad coreana, que además recrea y actualiza esa imagen del origen que forma parte de la construcción de identidades.

La localización centralizada ayuda a articular una cierta idea de vida asociativa y comunitaria dentro del espacio urbano, aún en el caso de la zona de Avellaneda, que como describimos antes es fuertemente comercial de forma extra-comunitaria. Quizás una muestra de esto, y de la creciente importancia de esta zona para la comunidad, sea que sobre esta calle se organizaron los últimos festejos anuales del día de Corea.

En este primer acercamiento al despliegue escénico de los restaurantes coreanos en Buenos Aires, pudimos observar cómo cada uno de éstos toma posición y reinvindica ciertos aspectos de la realidad sobre qué es ser coreano-argentino en la Ciudad de Buenos Aires en 2015. Mientras Kyung Mi Jong despliega en su imagen ideas de abundancia en la comida, con pinceladas de la Cora rural en la decoración, se muestra como restaurant al exterior pero se protege de la mirada extraña. Otros restaurantes, como 길정, son solo para entendidos, ofreciendo un espacio despojado de decoración que da la sensación de estar en casa, donde la comida llega y se come rápido. Estos casos conviven con Una canción coreana, que se ubica en el centro del opacado barrio tradicional, y a través de su gran ventanal se muestra para todo el que pase; presentando una imagen de Corea desarrollada y cosmopolita, pero a su vez con una cultura milenaria, que también se expresa en el legado alimentario.

Los restaurantes étnicos ubican la alimentación, práctica profundamente imbricada con la construcción de identidad, en el espacio de la ciudad; habilitando de este modo la creación de un espacio coreano en la diáspora.

A partir de este acercamiento a la problemática de los restaurantes coreanos en Buenos Aires, encontramos algunas dimensiones que aquí no fueron abordadas, pero se presentan fértiles para próximos estudios. Por un lado, una reflexión entorno a la "clase social" o al estrato socioeconómico de los clientes para comprender el funcionamiento de los restaurantes; y aún más, incluir esta dimensión en el análisis más amplio de los hábitos alimentarios de los migrantes coreanos. Por otro lado, estos restaurantes al tener dueños coreanos y empleados de otros grupos de migrantes o de la sociedad mayoritaria, presentan una instancia privilegiada para reflexionar sobre interculturalidad y relaciones laborales entre grupos migrantes.

\section{Referencias}

APPADURAI, Arjun. La modernidad desbordada. Dimensiones culturales de la globalización. Buenos Aires: Ediciones TrilceFCE, 2001.

ARFUCH, Leonor (comp.). Identidades, sujetos y subjetividades. Buenos Aires: Prometeo, 2005.

BARTHES, Roland. Toward a Psychosociology of Contemporary Food Consumption. En: COUNIHAN, Carole. y VAN ESTERIK, Penny (Eds.). Food and Culture. New York: Routledge, 2008.

BIALAGORSKI, Mirta. La presencia coreana en la Argentina: la construcción simbólica de una experiencia inmigratoria. Tesis (Doctorado en Ciencias Antropológicas) - Facultad de Filosofia y Letras. Universidad de Buenos Aires. Buenos Aires, 2002 BOURDIEU, Pierre. La distinción. Criterios y bases sociológicas del gusto. Madrid:Taurus, 1988.

BRUBAKER, Rogers. The 'diaspora' diaspora. Ethnic and Racial Studies, vol. 29, n. 1, p. 1-19, 2005

BRUNEAU, Michel. Diasporas et espaces transnationaux, Paris, Athropos, 2004.

CALVO, Manuel. Migration et alimentation. Social Science Information, v. 21, n. 3, p. 383-446, 1982.

CASTIGLIONE, Celeste. La inmigración coreana en la escuela media argentina: cinco etapas". En: XXVI CONGRESO DE LA ASOCIACIÓN LATINOAMERICANA DE SOCIOLOGÍA (ALAS), Guadalajara, 2007. En: http://www. aacademica.com/000-066/1003 Acceso en: 14 nov. 2014.

CHOI, In Bom. Korean diaspora in the making: its current status and impact on the Korean economy. En Bergsten, Fred y Choi, In Bom (eds.), The Korean diaspora in the world economy, Institute for International Economics, special report 15, 2003. CLIFFORD, James. Diasporas. Cultural Anthropology, vol. 9, n. 3, 1994

COHEN, Robin. Global Diasporas: An introduction. Washington: University of Washington Press, 1997

GARNIER, Julie. Faire avec les goûts des autres. Anthropology of food $\mathrm{n}^{\circ} 7$. Diciembre 2010. En: http://aof.revues.org/index6576. html Acceso en: 15 mar. 2011

GOFFMAN, Erving. La presentación de la persona en la vida cotidiana, Buenos Aires: Amorrortu, 1974.

GRIMSON, Alejandro. Los límites de la cultura. Crítica de las teorías de la identidad. Buenos Aires: Siglo Veintiuno Editores, 2011.

HALL, Stuart. ¿Quién necesita identidad?. En HALL Stuart. (comp) y DU GAY Paul. (comp). Cuestiones de identidad cultural. Buenos Aires: Amorrortu, 2011 
IMILAN, Walter. Restaurantes peruanos en Santiago de Chile: construcción de un paisaje de la migración. Revista de Estudios Sociales Universidad de los Andes, vol. 48, p. 15-28, 2014. En: http://dx.doi.org/10.7440/res48.2014.02 Acceso en: 14 jul. 2014.

KAPLAN, Adriana; CARRASCO, Silvia. Migración, cultura $y$ alimentación. Cambios y continuidades en la organización alimentaria, de Gambia a Cataluña. Barcelona: Bellaterra-Universitat Autònoma de Barcelona, 1999.

MEDINA, Xavier. Ciudad, etnicidad y alimentación. Restaurantes, tabernas y la construcción de territorios de identidad vascos en Barcelona. Zainak, vol. 24, p. 835-846, 2003. En: http:// www.euskomedia.org/PDFAnlt/zainak/24/08350846.pdf Acceso en: 15 jul. 2014.

MECCIA, Ernesto. El teatro que no representa. Una reseña tardía con algunas reflexiones actuales de La presentación de la persona en la vida cotidiana de Erving Goffman. Revista Argentina de Sociología n 4, p. 161-168, 2005.

MERA, Carolina. La inmigración coreana en Buenos Aires. Multiculturalismo en el espacio urbano. Buenos Aires: Eudeba, 1998. Migración coreana: identidades entre desplazamientos y anclajes. En Cohen, N. y Mera, C. (comp) Relaciones
Interculturales: experiencias y representación social de los migrantes. Buenos Aires: Antropofagia, 2005.

. El concepto de diáspora en los estudios migratorios: reflexiones sobre el caso de las comunidades y movilidades coreanas en el mundo actual. Revista de Historia n. 12, 2011. En: http://revele.uncoma.edu.ar/htdoc/revele/index.php/ historia/article/view/80/78 Acceso en: 12 sept. 2012

. Discovering the South through the Korean Diaspora. Koreans in Argentina and Latin America. En:VI WORLD KOREAN STUDIES CONGRESS, Transforming Korean Tradition: Past and Present. Seul, 2012. En: http://congress.aks. ac.kr/korean/files/2_1357261404.pdf Acceso en: 14 oct. 2014 MINTZ, Sidney. Tasting Food, Tasting Freedom: Excursions into Eating, Culture, and the Past. Boston: Beacon Press, 1996

SASSONE, Susana; MERA, Carolina. Barrios de migrantes en Buenos Aires: Identidad, cultura y cohesión socioterritorial. En:V CONGRESO EUROPEO CEISAL DE LATINOAMERICANISTAS, Bruselas 2007.Accesible en: http:// www.reseau-amerique-latine.fr/ceisal-bruxelles/MS-MIG/ MS-MIG-1-Sassone_Mera.pdf Acceso en: 15 jul. 2014

SHEFFER, Gabriel. Diaspora Politics: At home abroad. Cambridge: Cambridge University Press, 2003.

\title{
Korean restaurants in Buenos Aires city. Food, culture and identity in the diaspora
}

\begin{abstract}
This article proposes a reflection about Korean restaurants as places where different dimensions of the construction of identity of this group of migrants in Buenos Aires converge. Considering the hypothesis that these restaurants construct a narration about traditional food and about being Korean in Bs As, we recover the concept of front (Goffman, 1974) to describe the scenic strategies that are brought into play in such spaces. We were able to observe, that despite having similar characteristics, these restaurants present diverse narrations that articulate in different ways the heterogeneous cultural configurations of the Korean community in Buenos Aires
\end{abstract}

Keywords: migration; hood habits; restaurants; diaspora; identity

\section{Restaurantes coreanos na Cidade de Buenos Aires. Comida, cultura e identidade na diáspora}

\begin{abstract}
Resumo:
O artigo propõe uma reflexão em torno dos restaurantes coreanos como lugares onde confluem diferentes dimensões da construção da identidade de este grupo de migrantes em Buenos Aires. A partir da hipótese de que os restaurantes constroem um relato sobre a comida tradicional e sobre ser coreano em Buenos Aires, recuperamos o conceito de fachada (Goffman, 1974) para descrever as estratégias cênicas que se põem em jogo nesses espaços. Pudemos observar que apesar de terem características comuns, os restaurantes têm diferentes narrativas que articulam de modo diferenciado as heterogêneas configurações culturais da comunidade coreana em Buenos Aires.
\end{abstract}

Palavras chave: migração; hábitos alimentares; restaurantes; diáspora; identidade 